\title{
Descriptive epidemiology of body mass index of an urban adult population in western India
}

\author{
H C Shukla, P C Gupta, H C Mehta, J R Hebert
}

J Epidemiol Community Health 2002;56:876-880

\begin{abstract}
Study objective: To describe height, weight, and body mass index (BMI) of the adult urban population in Mumbai, western India and to estimate the prevalence and severity of thinness and overweight in this population. To describe the association of BMI with education, age, and tobacco habits in an urban Indian population.

Design: Cross sectional representative survey of 99598 adults (40 071 men and 59527 women). Setting: The survey was carried out in the city of Mumbai (formerly known as Bombay) in western India.

Participants: Men and women aged $\geqslant 35$ years who were residents of the main city of Mumbai. Main results: The mean height, weight, and BMI were 161.0 (SD 6.7) $\mathrm{cm}, 56.7$ (SD 11.0) kg, and 21.8 (SD 3.8) kg/m² for men and 148.0 (SD 6.2) cm, 49.8 (SD 1 1.2) kg, and 22.7 (SD 4.7$) \mathrm{kg} / \mathrm{m}^{2}$ for women, respectively. Some $19 \%$ of men and women were thin $\left(B M \mathrm{~K}<18.5 \mathrm{~kg} / \mathrm{m}^{2}\right)$, while $19 \%$ of men and $30 \%$ of women were overweight $\left(B M l \geqslant 25 \mathrm{~kg} / \mathrm{m}^{2}\right)$. Multivariable logistic regression analyses showed that age, level of education, and tobacco use were independently associated with BMI. The odds ratio (OR) and $95 \%$ confidence intervals $(\mathrm{Cl})$ for thinness $\left(\mathrm{BMl}<18.5 \mathrm{~kg} / \mathrm{m}^{2}\right)$ were $\mathrm{OR} 6.52$, $95 \% \mathrm{Cl} 5.38$ to 7.89 for men and $\mathrm{OR} 4.83,95 \% \mathrm{Cl} 3.71$ to 6.28 for women, respectively, $(\mathrm{p}<0.001)$ for the lowest level of education (illiterate group). The OR and $95 \% \mathrm{Cl}$ for overweight were $2.25,2.20$ to 2.58 for college educated men and $1.90,1.64$ to 2.20 for college educated women, respectively, $p<0.001$. Both smoking $(2.33,2.09$ to $2.59 ; 2.89,1.77$ to 4.72 for men and women, respectively, $p<0.001)$ and smokeless tobacco use $(1.65,1.52$ to $1.80 ; 2.26,2.14$ to 2.38 for men and women, respectively $p<0.0001$ ) were significantly associated with low BMI.

Conclusions: Sequelae of thinness and overweight represent major public health problems. The results of this study, indicating an equal prevalence of thinness and overweight in an urban area and their association with age, level of education, and tobacco use raise concerns of an emerging public health crisis in urban India.
\end{abstract}

See end of article for authors' affiliations

Correspondence to: Heema Shukla, University of Westminster, Room 514 9-18 Euston, Centre, London NW1 3ET, UK; shuklah@wmin.ac.uk

Accepted for publication 19 March 2002

in

ndia is undergoing rapid economic transition. At this stage in the associated epidemiological transition, the country is facing the double burden of communicable and noncommunicable diseases. As in all such transitions, nutrition plays a central part. ${ }^{12}$

Obesity, representing one extreme of the continuum, is a preventable risk factor for chronic degenerative diseases ${ }^{34}$ while chronic energy deficiency (CED), though less directly "preventable," is associated with impaired physical capacity, reduced economic productivity, ${ }^{67}$ increased mortality, ${ }^{89}$ and poorer reproductive outcomes. ${ }^{10-12}$ Routine monitoring of nutritional status through the collection of anthropometric data is a simple approach that is both economical and can be rapidly applied to large numbers of people. The body mass index (BMI, weight $(\mathrm{kg}) /$ height $\left.(\mathrm{m})^{2}\right)$ is a useful index of relative weight that can be applied to define obesity ${ }^{13}$ and $\mathrm{CED}^{14}{ }^{15}$ and can be used to assess individual and community nutritional status. ${ }^{16}$ With its huge population and extremes of economic conditions, India is in a unique position in its epidemiological and nutrition transition that may presage the experience of many developing countries. Although the National Nutrition-Monitoring Bureau (NNMB $)^{17}$ has published the BMI profile of a representative rural Indian population, there is a paucity of data on the BMI distribution of representative adult Indian urban populations-the group at highest risk of the extremes of the current transition. We present here the BMI profile and reference data from a baseline survey of a cohort study of an urban adult population in Western India. In describing, for the first time, the distribution of BMI of a broadly representative urban Indian population in relation to educational background, age, and tobacco use, we are able to identify groups at risk of extreme forms of malnutrition. This allows for discussion of the implications for future research and public health policy.

\section{METHODS}

The anthropometric data presented in this report were obtained from a baseline cross sectional survey conducted between 1991 and 1994 for a cohort study on tobacco attributable mortality. ${ }^{18}$ The survey was carried out in the main city of Mumbai. A sampling frame was constructed from the electoral rolls. The sampling unit was a "polling station", consisting of 1000-1500 eligible voters. Rolls were assumed to be complete, as they are updated before every major election through house to house visits. Electoral rolls were organised by geographical areas. The selection of polling stations was done in a non-random manner to exclude those with apartments having high security as it became evident during the pilot study that it would not be possible to gain access to these apartments.

Investigators approached all people aged $\geqslant 35$ years (cut off chosen because of the overall goal of studying tobacco attributable mortality in the cohort) listed in the selected polling stations for interview and anthropometric measurements. People not present on the voters' list also were interviewed

Abbreviations: $\mathrm{BMI}$, body mass index; $\mathrm{CED}$, chronic energy deficiency 
Table 1 Age and gender specific anthropometric values (mean (SD))

\begin{tabular}{|c|c|c|c|c|c|c|c|c|}
\hline \multirow[b]{2}{*}{ Age $(y)$} & \multicolumn{4}{|l|}{ Men } & \multicolumn{4}{|l|}{ women } \\
\hline & $\mathrm{N}$ & Height $(\mathrm{cm})$ & Weight (kg) & $\mathrm{BMI}\left(\mathrm{kg} / \mathrm{m}^{2}\right)$ & $\mathrm{N}$ & Height $(\mathrm{cm})$ & Weight (kg) & BMI $\left(\mathrm{kg} / \mathrm{m}^{2}\right)$ \\
\hline $35-44$ & 15421 & $162.1(6.7)$ & 57.8 (11.0) & $22.0(3.7)$ & 24839 & 149.1 (5.9) & 50.4 (10.9) & $22.6(4.5)$ \\
\hline $45-54$ & 10636 & $161.1(6.6)$ & $57.3(11.1)$ & 22.1 (3.8) & 17054 & $148.1(6.0)$ & 50.9 (11.4) & $23.2(4.8)$ \\
\hline $55-64$ & 8272 & $160.1(6.6)$ & $56.1(10.7)$ & 21.8 (3.7) & 11349 & $146.8(6.1)$ & 49.4 (11.1) & $22.9(4.7)$ \\
\hline $65-74$ & 4439 & $159.6(6.4)$ & $54.4(10.6)$ & $21.3(3.8)$ & 4867 & $145.2(6.3)$ & 46.4 (11.1) & $21.9(4.8)$ \\
\hline $75-84$ & 1091 & $158.8(6.9)$ & $52.1(10.1)$ & $20.6(3.6)$ & 1153 & $143.7(6.8)$ & 43.9 (10.5) & $21.2(4.7)$ \\
\hline $85+$ & 212 & $156.3(7.0)$ & $48.3(8.9)$ & 19.8 (3.3) & 265 & $141.0(7.5)$ & $38.6(9.2)$ & $19.4(4.5)$ \\
\hline Total & 40071 & $161.0(6.7)$ & 56.7 (11.0) & $21.8(3.8)$ & 59527 & $148.0(6.2)$ & $49.8(11.2)$ & 22.7 (4.7) \\
\hline
\end{tabular}

and included in the sample if their residence status was confirmed by their having a "ration card". These cards, issued by the Bombay Municipal Corporation, act as a proxy for residence cards and permit access to all city and state government services (including receiving certain food items at subsidised prices). Such people comprised about 5\% of the sample. Less than $1 \%$ of people approached did not agree to be interviewed and provide anthropometric measurements. A total of 99958 adults, consisting of 40071 men and 59527 women, were recruited and surveyed. The study satisfied all criteria of ethical treatment of human subjects; especially those formulated by the Indian Council of Medical Research.

The survey included two components, measurement of height, weight, blood pressure, and interviewer administration of a structured questionnaire to obtain information on age, occupational history, education, religion, language, and tobacco related behaviour. Weight was measured using bathroom scales accurate to $0.5 \mathrm{~kg}$. The scale was kept on a flat surface and the subject was requested to step on it in bare feet without holding on to anything. Subjects were measured in normal apparel, which, in Mumbai is light cotton because of the tropical weather throughout the year. The weight was recorded to the nearest kg. Height was measured using a specially constructed instrument consisting of a steel platform to which was attached a steel measure tape. With the subject standing erect on the steel platform, the tape was pulled vertically above the head, and then brought down to touch the flat ruler placed horizontally on the crown of the head. Height was recorded to the nearest $\mathrm{cm}$.

Table 2 Prevalence (\%) of thinness and overweight*

\begin{tabular}{|c|c|c|c|c|c|c|c|c|}
\hline \multirow{2}{*}{$\begin{array}{l}\text { Age (y) by } \\
\text { gender }\end{array}$} & \multicolumn{4}{|c|}{ Grades of thinness } & \multicolumn{4}{|c|}{ Grades of overweight } \\
\hline & 1 & 2 & 3 & Total & 1 & 2 & 3 & Total \\
\hline \multicolumn{9}{|l|}{ Men } \\
\hline $35-44$ & 10.1 & 4.3 & 3.9 & 18.3 & 17.5 & 2.3 & 0.0 & 19.8 \\
\hline $45-54$ & 10.4 & 4.0 & 4.0 & 18.4 & 18.3 & 2.7 & 0.0 & 21.0 \\
\hline $55-64$ & 9.2 & 4.7 & 5.1 & 19.0 & 16.6 & 2.1 & 0.0 & 18.7 \\
\hline $65-74$ & 10.7 & 5.3 & 7.5 & 23.5 & 15.1 & 1.6 & 0.0 & 16.7 \\
\hline $75-84$ & 13.4 & 8.1 & 9.0 & 30.5 & 11.4 & 1.1 & 0.0 & 12.7 \\
\hline $85+$ & 14.6 & 9.4 & 12.3 & 36.3 & 6.1 & 0.5 & 0.0 & 6.6 \\
\hline Total & 10.2 & 4.5 & 4.8 & 19.5 & 17.0 & 2.2 & 0.0 & 19.2 \\
\hline \multicolumn{9}{|l|}{ Women } \\
\hline $35-44$ & 9.9 & 4.6 & 4.7 & 19.2 & 21.9 & 6.2 & 0.1 & 28.2 \\
\hline $45-54$ & 8.2 & 3.9 & 4.9 & 17.0 & 24.9 & 8.0 & 0.2 & 33.1 \\
\hline $55-64$ & 8.0 & 3.8 & 6.4 & 18.2 & 23.6 & 7.1 & 0.1 & 30.8 \\
\hline $65-74$ & 9.7 & 4.6 & 10.0 & 24.3 & 18.9 & 5.4 & 0.2 & 24.5 \\
\hline $75-84$ & 11.4 & 6.7 & 12.0 & 30.1 & 16.3 & 3.6 & 0.3 & 20.2 \\
\hline $85+$ & 16.6 & 10.9 & 20.8 & 48.3 & 7.9 & 1.5 & 0.4 & 9.8 \\
\hline Total & 9.1 & 4.3 & 5.7 & 19.1 & 22.7 & 6.8 & 0.2 & 29.7 \\
\hline
\end{tabular}

*Thinness is defined as (a) grade 1 (mild thinness) BMI $=17-18.49$ $\mathrm{kg} / \mathrm{m}^{2}$ (b) grade 2 (moderate thinness BMI 16-16.99 (c) grade 3 (severe thinness) BMI <16.0. Overweight is defined as (a) grade 1 overweight $\mathrm{BMI}=25.0-29.99(\mathrm{~b})$ grade 2 overweight $\mathrm{BMl}$ $=30-39.99$ and (c) grade 3 overweight $B M I \geqslant 40$.
All data were entered directly in a handheld computer in the field and transferred to a PC once a week in the Project office. Based on BMI, the subjects were classified into categories of thinness or overweight according to the WHO classification. ${ }^{19}$ Thinness is defined as (a) grade 1 (mild thinness) $\mathrm{BMI}=17-18.49 \mathrm{~kg} / \mathrm{m}^{2}$, (b) grade 2 (moderate thinness) BMI 16-16.99 kg/m², (c) grade 3 (severe thinness) BMI $<16.0 \mathrm{~kg} / \mathrm{m}^{2}$. Overweight is defined as (a) grade 1 overweight $\mathrm{BMI}=25.0-29.99 \mathrm{~kg} / \mathrm{m}^{2}$, (b) grade 2 overweight BMI kg/m² $=30-39.99$, and (c) grade 3 overweight $\mathrm{BMI} \geqslant 40$ $\mathrm{kg} / \mathrm{m}^{2}$. Respondents were classified according to present and past tobacco use as (a) having no habit (past or present), (b) past tobacco user, (c) present smoker, (d) present smokeless tobacco user, and (e) present mixed habit (smokeless and smoking). For analysis of educational background, respondents were classified as (a) illiterate-received no education, (b) primary—attended only primary school, (c) middle-received education through middle school, (d) secondary-received education through secondary level, (e) college-those who have received education past secondary level. Descriptive statistics (mean, standard deviations, centiles, and proportions within categories) were calculated for the total survey population and by age, educational background, and tobacco use.

Multivariable analysis was performed using logistic regression. The response variable, BMI, was converted into a dichotomous variable by using two cut off points: 18.5 and 25.0 $\mathrm{kg} / \mathrm{m}^{2}$ for analysis of thinness and $18.5-25$ and $25-30 \mathrm{~kg} / \mathrm{m}^{2}$ were used for analysis for predictors of overweight. Three possible models corresponding to these two cut off points were fit. Age (in five year age groups), education, and tobacco use were fit as independent variables in the final model.

\section{RESULTS}

Table 1 shows the mean age specific anthropometric values for men and women. Men were $13 \mathrm{~cm}$ taller and $7 \mathrm{~kg}$ heavier

Table 3 Adjusted odds ratio (OR) for thinness by level of education and tobacco use*

\begin{tabular}{lll}
\hline & OR $(95 \% \mathrm{CI}) \dagger$ \\
\cline { 2 - 3 } Variable & Women & Men \\
\hline $\begin{array}{lll}\text { Educational status } \\
\quad \text { Illiterate }\end{array}$ & $4.83(3.71$ to 6.28$)$ & $6.52(5.38$ to 7.89$)$ \\
$\quad$ Primary & $2.25(1.73$ to 2.93$)$ & $3.74(3.15$ to 4.44$)$ \\
$\quad$ Middle & $2.33(1.78$ to 3.05$)$ & $2.48(2.09$ to 2.95$)$ \\
$\quad$ Secondary & $1.78(1.33$ to 2,38$)$ & $2.10(1.73$ to 2.55$)$ \\
$\quad$ College & 1.00 & 1.00 \\
Tobacco use & & 1.00 \\
$\quad$ No tobacco use & 1.00 & $1.65(1.52$ to 1.80$)$ \\
$\quad$ Smokeless & $2.26(2.14$ to 2.38$)$ & $2.33(2.09$ to 2.59$)$ \\
$\quad$ Smoking & $2.89(1.77$ to 4.72$)$ & $2.46(2.29$ to 2.87$)$ \\
$\quad$ Mixed & $3.12(1.80$ to 5.41$)$ & \\
\hline
\end{tabular}

* Results are controlled for age and either tobacco use (for the educational status results) or educational status (for the tobacco use results). †All ORs were significant at $p<0.0001$. 
Table 4 Adjusted odds ratio (OR) for overweight by level of education and tobacco use*

\begin{tabular}{lll}
\hline & OR $(95 \% \mathrm{Cl}) \dagger$ & \\
\cline { 2 - 3 } & Men & Women \\
\hline $\begin{array}{l}\text { Educational status } \\
\text { Illiterate }\end{array}$ & 1.00 & 1.00 \\
Primary & $1.35(1.21$ to 1.49$)$ & $1.44(1.38$ to 1.52$)$ \\
Middle & $1.57(1.41$ to 1.75$)$ & $1.47(1.38$ to 1.57$)$ \\
Secondary & $1.59(1.40$ to 1.80$)$ & $1.47(1.33$ to 1.63$)$ \\
$\quad$ College & $2.25(2.00$ to 2.58$)$ & $1.90(1.64$ to 2.20$)$ \\
Tobacco use & & 1.00 \\
No tobacco use & 1.00 & $0.72(0.69$ to 0.76$)$ \\
Smokeless & $0.82(0.77$ to 0.88$)$ & $0.59(0.38$ to 0.92$)$ \\
Smoking & $0.77(0.70$ to 0.84$)$ & $0.77(0.45$ to 1.32$)$ \\
$\quad$ Mixed & $0.72(0.66$ to 0.80$)$ & 0.75 \\
\hline
\end{tabular}

*Results are controlled for age and either tobacco use (for the educational status results) or educational status (for the tobacco use results). †All ORs were significant at $p<0.0001$ except the one marked $^{\text {NS }}$.

compared with women, but the relative weight of women (expressed as BMI) was higher. Younger cohorts tended to be taller and heavier. Men, 35-44 years old were, on average, 5.8 cm taller, $9.5 \mathrm{~kg}$ heavier, and had BMI $2.2 \mathrm{~kg} / \mathrm{m}^{2}$ higher compared with the most elderly ( $85+$ years). The youngest women were, on average, $8.1 \mathrm{~cm}$ taller, $11.8 \mathrm{~kg}$ heavier, and had a BMI $3.2 \mathrm{~kg} / \mathrm{m}^{2}$ higher compared with the eldest women

In men, prevalence of thinness and overweight were similar ( $19.5 \%$ and $19.2 \%$ respectively) (table 2 ). By contrast, in women, there was a significantly higher prevalence of overweight $(29.7 \%)$ compared with thinness (19.1\%). The prevalence of severe thinness $\left(\mathrm{BMI}<16 \mathrm{~kg} / \mathrm{m}^{2}\right)$ was similar in both men and women $(4.8 \%$ and $5.7 \%$, respectively). More women were obese $\left(\mathrm{BMI} \geqslant 30 \mathrm{~kg} / \mathrm{m}^{2}\right)$ compared with men $(6.8 \% v 2.2 \%)$ and $0.2 \%$ of women had a $\mathrm{BMI} \geqslant 40 \mathrm{~kg} / \mathrm{m}^{2}$. In both men and women, the older cohorts $(75+$ years $)$ had higher prevalence of thinness while obesity was highest in the 45-54 years old cohort. Table 3 and 4 give the odds ratio for thinness and obesity associated with levels of education (adjusted for age and tobacco use) and for tobacco use (adjusted for age and level of education).

\section{DISCUSSION}

The Mumbai population was on average, $12 \mathrm{~cm}$ shorter, $24 \mathrm{~kg}$ lighter, and had a BMI $4 \mathrm{~kg} / \mathrm{m}^{2}$ lower than the UK population and the USA population. ${ }^{20}$

Previous published studies on BMI in India have reported either a high prevalence of thinness with a low prevalence of overweight or a low prevalence of thinness and a high prevalence of overweight. This contradictory reporting may be attributable to differences in locality (urban/rural) or population sample (high socioeconomic/low socioeconomic). A representative survey conducted in rural areas by NNMB found that over $40 \%$ of the women were thin while prevalence of overweight was only $6.6 \% .{ }^{22}$ A previous study from Mumbai reported a higher prevalence of overweight (44\%). ${ }^{23}$ However, sampling volunteers from members of clubs could have introduced a bias towards overweight in that study. A five city study that included Mumbai as one of its sites, reported a higher prevalence of overweight (37.5\%) and a lower prevalence of thinness $(5 \%)$ in women. ${ }^{24}$ Published data from surveys in Delhi, another major city in India, reported 23\%-25\% of men were overweight. ${ }^{25}{ }^{26}$ However, the reported prevalence of being overweight in women was highly divergent $135 \%$ and $60 \%$ ) in these two studies. A prevalence of $21 \%-27 \%$ for overweight has been reported from other urban areas in India. ${ }^{27} 28$ In general, previous studies in urban areas have focused mainly on the prevalence of obesity, but the prevalence of

\section{Key points}

- Urban India faces the public health burden associated with both the extremes of malnutrition-that is, thinness and overweight.

- The "at risk" groups for thinness are illiterate/less educated and elderly while the college educated middle age groups are "at risk" of overweight.

- Tobacco use including oral use la common practice in India) is an independent risk for thinness in this population.

- There is a need to integrate education and health policy for interventions to alleviate thinness and curb overweight.

thinness has not been reported thus far except in one urban slum population, which reported that $36.7 \%$ were underweight and $11.6 \%$ were overweight. ${ }^{30}$

The BMI profile presented in this paper is from the largest urban survey done on adults in India to date. Besides being one of the largest cities in India, Mumbai is the country's financial centre and is host to people from all states of India. The age distribution of the study sample was similar to that of urban India. Literacy in the study sample was $87.6 \%$ and $54.7 \%$ compared with $81.3 \%$ and $62.5 \%$ for urban India for men and women, respectively (15-59 age group). ${ }^{31}$ We excluded affluent housing residents and adults aged 20-34 years of age. While this might be seen as a limitation, it can be argued that middle to low income strata form a substantial segment of the population and are the groups in whom the epidemiological transition will have the most impact. The findings presented in this paper provide evidence that both overweight and thinness are equally prevalent in the urban population of Mumbai.

Emerging problems related to overweight against a background of chronic underweight in large segments of the population raises important questions about policies aimed at health promotion. For example, in a country with a preponderance of overweight a recommendation can be targeted at lowering BMI values without much concern for thinness (except among people with eating disorders). On the other hand, in a country with a preponderance of thinness, a recommendation can be targeted at increasing body weights without much concern for inducing obesity or overweight related illness. In this study, we have found that it will be necessary to attend to both underweight and overweight portions of the distribution in identifying vulnerable targeting interventions. Because age, education, and tobacco use are independently associated with BMI, such targeting will need to take these factors into account.

\section{Age and BMI}

Age seems to be an independent risk factor for thinness. In interpreting this association, it must be noted that in cross sectional surveys the observed associations between age and BMI most probably reflect both the secular and the longitudinal changes in the physical status. Despite this, a high prevalence of thinness among the aged is of concern. This is in contrast with observations in elderly populations in affluent countries such as the UK, where $5 \%$ of men and $6 \%$ of women aged $75+$ years are thin, and $64 \%$ men and $57 \%$ women are overweight. ${ }^{20}$ There may be many reasons for higher prevalence of thinness among elderly Indians. Because of "cohort" effects, older people may have been thinner throughout their life span. Also, in the older age groups, mortality and morbidity may influence the anthropometric profile with thinness being associated with longevity. To some extent, thinness can be seen as an adaptation consonant with long term survival. On the other hand, loss of income and independence may have caused a drop in the BMI in the elderly group. It is most likely that a combination of all these factors influences BMI in the 


\section{Policy implications}

- In India, and in many developing countries, health and nutrition policies would need to tackle the high prevalence of thinness as well as overweight.

- Appropriate messages about thinness need to be targeted towards less educated, lower socioeconomic groups, and the elderly population. This has important implications for agricultural and food market price support policies.

- Unlike in the West, where overweight is more prevalent among the economically deprived, in India messages about overweight need to be directed towards more highly educated and in upper socioeconomic groups. As in the West, control of overweight should begin early in life; hence, messages should target younger people.

- Weight gain or improvement in BMI can be projected as a specific desirable outcome of tobacco control policies and tobacco education programmes, especially those directed towards less educated segments of the population.

- Policy consideration should be given to people, especially women, who may use smoking as a means to control body weight.

elderly population. Follow up of this cohort may help to explain the observed age-BMI association.

\section{Education and BMI}

We found that low BMI was associated with lower educational attainment in both men and women. From the 26 populations studied in the MONICA study, no significant association was found between education and BMI in men from 18 countries and an inverse association was found in six countries. ${ }^{32}$ Education level and BMI were positively associated only in men from Moscow and Poland. By contrast, in women, 22 of 26 countries showed an inverse relation between education and BMI. An inverse association is the norm in many affluent countries, most notably the US. ${ }^{33}$ Clearly, the education-BMI association is not static but changes over time and with the epidemiological transition. For example, although in the UK there currently exits an inverse relation between socioeconomic class and BMI, a positive association between socioeconomic status and overweight existed in the UK in the 1950s to early $70 s^{34}$ One explanation for this "inversion" in the association between educational level and BMI is the relation between occupation and education. In countries in transition, where less educated people are in labour intensive occupations and people with higher education are living a more sedentary lifestyle, a positive association between education and BMI will be seen, as in this study. In economically advanced countries, lower education may be associated with higher unemployment or low paid jobs that are not necessarily labour intensive. Leisure time physical activity may be the major determinant of BMI. Increased health awareness and access to recreational facilities among the highly educated (affluent) groups compared with the less educated would result in an inverse relation between education and BMI. For example, in the USA, obesity is twice as high in men with $<$ a 9 th grade education $(21.7 \%)$ compared with college graduates $(11 \%)$ and two and half times higher in women with $<$ a 9 th grade education $(26.6 \%)$ compared witho graduates $(10.0 \%){ }^{35}$ Female college graduates in Mumbai have a similar prevalence of obesity (11.1\%) as Americans; however, illiterate Indian women have a lower prevalence of obesity $(5.1 \%)$ and a higher prevalence of thinness $(24.3 \%)$. Indian men have a very low prevalence of obesity overall. However, prevalence was highest $(3.6 \%)$ in graduate men.

\section{Tobacco use and BMI}

In our study all forms of tobacco use were independently associated with lower BMI. Lower BMI in smokers compared with non-smokers has been reported in many studies. ${ }^{36}{ }^{37}$ The smoking-BMI association has been attributed to the effect of smoking on physiological processes that lead to changes in appetite, food preferences, and basal metabolic rate. ${ }^{38-40}$ There have been no previous reports on smokeless tobacco use and, as far as we are aware, this is the first to show smokeless tobacco use as an independent risk for low BMI. This merits further investigation as tobacco use in India takes a variety of smokeless and smoking forms, of which cigarettes are only a minor part. ${ }^{41}$

\section{Conclusions}

This study showed that both chronic underweight and overweight are equally present in an urban population of India, with important public health implications for the burden of diseases associated with both extremes of physical status. Moreover, findings relating age, education, and tobacco use to BMI provide information for further study and formulation of health policy. High prevalence of thinness in the less educated urban populations coupled with a high prevalence of overweight among the more educated is a matter of great concern. The World Bank estimates that malnutrition costs India at least US\$10 billion annually in terms of lost productivity, illness, and death. ${ }^{42}$ If the present trend of rural to urban migration continues, less educated agricultural male labourers are the most likely to migrate because industrialisation and the diminishing contribution of agriculture to GDP may force them to seek alternative sources of income in urban areas. The size of the less educated urban population is a key determinant of the prevalence of thinness. Therefore, the burden of diseases associated with thinness will most probably continue to be a major public health challenge in urban India. As migration continues, the transition from low to higher education occurs in the middle class and those aspiring to middle class status. Thus, the burden of overweight associated diseases also will continue to increase. To meet this double burden of public health challenges, policy makers may need to consider the formulation of an integrated health and education policy that aims to improve educational status and alleviate illiteracy related thinness yet curb the increase of obesity in urban India.

The other vulnerable group at risk of thinness is the elderly. This segment of the population is growing worldwide and concern for the nutritional status of the elderly has been expressed in many countries. The BMI distribution observed in the elderly in this urban survey provides evidence that provisions for the care of this group need to be considered carefully by health care policy makers.

Further studies on other determinants of adult BMI and on the distribution of BMI in children and young adults in urban India are urgently required to obtain a fuller picture of high risk populations for both extremes of BMI.

\section{ACKNOWLEDGEMENTS}

Thanks are due to Prabhat Jha, Alan Lopez, D M Parkin, Sir Richard Peto, and R Sankaranarayanan for their valuable comments and advice on the conduct of the study and M Pednekar for help in programming and computation help is thankfully acknowledged.

\section{Authors' affiliations}

H C Shukla, Biomedical Sciences, University of Westminster, London, UK

P C Gupta, H C Mehta, Epidemiology Research Unit, TATA Institute of Fundamental Research, Mumbai, India

J R Hebert, Department of Epidemiology and Biostatistics, University of South Carolina, USA

Funding: This study was conducted in collaboration with the International Agency for Research on Cancer, France, (Collaborative Research Agreement No.DEP/89/12), the ICRF/MRC Clinical Trial Service Unit, University of Oxford, UK, the World Bank, Washington DC and the World Health Organisation, Geneva and they all provided part funding for the study.

Conflicts of interest: none 


\section{REFERENCES}

1 Romieu I, Hernandez-Avila M, Rivera JA. Dietary studies in countries experiencing a health transition: Mexico and Central America. Am J Clin Nutr 1997:65:1159-65S

2 Rosenkrantz B. Public health and the state: changing views in Massachusetts, 1842-1936. Cambridge, MA: Harvard University, 1972

3 WHO. Diet, nutrition and prevention of chronic diseases. WHO Tech Report Series No 797. Geneva: World Health Organization, 1990.

4 WHO. Obesity: preventing and managing the global epidemic. Report of WHO consultation on Obesity, Geneva June 5-7 1997. Geneva: World Health Organization, 1998.

5 Durnin JVGA. Low body mass index, physical work capacity and physical activity levels. Eur J Clin Nutr 1994; 48:S39-44.

6 Kennedy E, Garcia M. Body mass index and economic productivity. Eur J Clin Nutr 1994;48:S45-55.

7 Untoro J, Gross R, Schultink W, et al. The association between BMI and haemoglobin and work productivity among Indonesian female factory workers. Eur J Clin Nutr 1998:52:131-5.

8 Campbell P, Ulijasek SJ. Relationships between anthropometry and retrospective morbidity in poor men in Calcutta, India. Eur J Clin Nutr 1994;48:507-12.

9 National Institute of Nutrition. Body mass index and mortality rates: ten year retrospective study. In: Annual Report, 1989-90. Hyderabad: NIN, 1991

10 World Health Organization. Maternal anthropometry and pregnancy outcomes: a WHO collaborative project. Bull World Health Organ 1995;73:1-98

11 Schieve LA, Cogswell ME, Scahlon KS, et al. Prepregnancy body mass index and pregnancy weight gain: associations with preterm delivery. The NMIHS Collaborative Study Group. Obstet Gynecol 2000;96:194-200.

12 Kusin JA, Kardjote, Renqvist WH. Maternal body mass index: the functional significance during reproduction. Eur J Clin Nutr 1994;48:S56-67

13 Garrow JS Obesity and related diseases. Edinburgh: Churchil Livingstone, 1988.

14 Shetty PS, James WPT. Body mass index: a measure of chronic dietary energy deficiency in adults. Rome: Food and Agriculture Organization of the United Nations, 1994

15 Ferro-Luzzi A, Sette S, Franklin M, et al. A simplified approach of assessing adult chronic energy deficiency. Eur J Clin Nutr 1992:46:173-86.

16 Bailey KV, Ferro-Luzzi A. Use of body mass index of adults in assessing individual and community nutritional status. Bull World Health Organ 1995;73:673-80

17 Naidu NA, Rao PN. Body mass index: a measure of nutritional status in Indian population. Eur J Clin Nutr 1994:48:S131-40.

18 Gupta PC, Mehta HC. Cohort study of all-cause mortality among tobacco users in Mumbai, India. Bull World Health Organ 2000;78:877-83.

19 World Health Organization. Physical status: the use and interpretation of anthropometry. Report of a WHO Expert Committee. Geneva: WHO, 1995.

20 Prescott-Clarke P, Primatesta P. Health survey of England 1996. Department of Health at URL: http://www.official-documents.co.uk/ document/doh/survey96/tab7-10.htm
21 National Centre for Health Statistics. Height, weight and BMI data tables from NHANES III at URL. http://www.cdc.gov/nchs/about/ major/nhanes

22 Reddy V, Rao PN, Sastry J, et al. Nutrition trends in India. Hyderabad: National Institute of Nutrition, 1993.

23 Dhurandhar NV, Kulkarni PR. Prevalence of obesity in Bombay. Int J Obes 1992;16:367-75.

24 Singh RB, Beegom R, Mehta AS, et al. Social class, coronary risk and undernutrition, a double burden of diseases, in women during transition in five Indian cities. Int J Cardiol 1999;69:139-47.

25 Chadha SL, Gopinath N, Katyal I, et al. Dietary profile of adults in an urban and rural community. Indian J Med Res 1995;101:258-67.

26 Gopalan C. Obesity in the urban Indian 'middle class'. Bulletin of the Nutrition Foundation of India 1998; Jan.

27 Rao VK, Rau P, Thimmayamma BVS. Nutritional anthropometry of Indian adults. Indian J Nutr Dietetics 1986;23:239-56.

28 Sood K, Gupta K, Ahluuwalia K, et al An epidemiological study of obesity in Shimla town. Indian J Med Sci 1996;50:362-4.

29 Singh RB, Niaz MA, Thakur AS, et al. Social class and coronary artery disease in an urban population of North India in the Indian lifestyle and heart study. Int J Cardiol 1998;64:195-203.

30 NIN. Report of urban survey-slums (1993-94). Hyderabad: National Nutrition Monitoring Bureau, 1996.

31 Registrar General of India. Literacy rate by important age groups and sex. 1991 Census data online at URL: http://www.censusindia.net

32 Molarius A, Seidell JC, Sans S, et al. Educational level, relative body weight and changes in their association over 10 years: an International Perspective from the WHO MONICA Project. Am J Public Health 2000;99:1260-8.

33 Flegal KM, Carroll MD, Kuczmarski RJ, et al. Overweight and obesity in the United States: prevalence and trends, 1960-1994. Int J Obes Relat Metab Disord 1998;22:39-47.

34 Sobal J, Stunkard AJ. Socioeconomic status and obesity: a review of the literature. Psychol Bull 1989;105:260-75.

35 National Centre for Health Statistics. Prevalence of overweight and obesity among adults in the United States. National Health Survey Interview. CDC/NCHS, 1997 at URL: http://www.cdc.gov/nchs/ products/pubd/hestats/3and4/overweight.PDF

36 Molarius A, Seidall JC, Kuulasmaa K, et al. Smoking and relative weight: an international perspective WHO MONICA project. J Epidemiol Community Health 1997;51:252-60.

37 Rasky E, Stronegger WJ, Friedl W. The relationship between body weight and patterns of smoking in women and men. Int J Epidemiol 1996;25:1208-12.

38 Margetts BM, Jackson AA. Interactions between people's diet and their smoking habits: the dietary and nutritional survey of British adults. BM 1993;307:1381-4.

39 Perkins KA, Sexton JE, DiMarco A. Acute thermogenic effects of nicotine and alcohol in healthy male and female smokers. Physiol Behav 1996;60:305-9.

40 Hofstetter A. Increased 24-hour energy expenditure in cigarette smokers. N Engl J Med 1986:314:79-82.

41 Bhonsle RB, Murti PR, Gupta PC. Tobacco habits in India. In: Gupta PC Hamner JE, Murti PR, eds. Control of tobacco-related cancers and other diseases. Bombay: Oxford University Press, 1992.

42 World Bank. Country Brief-India 2000 URL: http://

www.worldbank.org/sar 